\title{
Sporotrichosis Outburst after Cancer Chemotherapy in a Dog
}

\author{
Leonardo Tótola da Silva', Neriana Rosseti Intra², Carolina Magri Ferraz², Jeanne Saraiva da Paz ${ }^{3}$, \\ Ana Carolina de Jesus Pinto ${ }^{3}$, Bruna Voltolin de Sena ${ }^{3}$, Rodrigo dos Santos Horta ${ }^{4}$, Fabio Ribeiro Braga ${ }^{4}$, \\ Fernando Luiz Tobias ${ }^{4} \&$ Priscila Camargo Granadeiro Farias ${ }^{4}$
}

\begin{abstract}
Background: Sporotrichosis is a dermatozoonosis that affects mammals in general, with the domestic feline (Felis catus) being the most epidemiologically important species. However, diagnosis of this disease in dogs is important considering the proximity with people and with other communicants. The epidemiology of sporotrichosis is already known in some states of Brazil, especially in the southeast region, but to the best of our knowledge there are no reports of sporotrichosis in non-human species in the state of Espírito Santo. This paper aimed at describing the first case of canine sporotrichosis in Espírito Santo, Brazil.

Case: A 10 year-old Bull Terrier male dog was presented with nodular non-ulcerated lesions on the head and nodular ulcerated lesion on the nasal planum. The dog had a previous diagnosis of a low-grade mast cell tumour and palpebral melanoma. Mast cell tumour was treated with scrotum ablation (and orchiectomy) and bilateral inguinal lymph node removal, followed by chemotherapy with twelve intravenous infusion of vinblastine, along with prednisolone. Cutaneous lesions in the head and nasal planum appeared two months after finishing chemotherapy. At further anamnesis, the pet's responsible reported that the dog had the habit of hunting cats that entered the residence, which raised the hypothesis of sporotrichosis. An undiagnostic cytology was performed, followed by a fungal culture, positive for Sporothrix schenckii. Treatment was then initiated with itraconazol (Oficial generic drug), at a dose of $10 \mathrm{mg} / \mathrm{kg} / \mathrm{SID}$, until clinical remission, obtained after 60 days, maintaining it for 60 more days. Patient showed completed recovery, with no further complatints after a follow-up of more than 220 days.

Discussion: Sporotrichosis is considered a rare disease in dogs, with isolated cases in the literature. The dog of the present report was diagnosed with sporotrichosis two months after the end of a chemotherapy treatment for a mast cell tumour. Therefore, it is suggested that the patient in this study was infected during an immunosuppressive phase. The same can occur with other immunosuppressive treatments, such as glucocorticoid, also included in the chemotherapy treatment of this patient, calcineurin inhibitors (cyclosporine) and mercaptopurine derivatives (azathioprine). Cytology is usually unconclusive for such lesions in dogs, once only a few yeast might be present. Nevertheless, the definitive diagnosis was obtained through fungal microculture. Treatment with itraconazol was successful but dogs might also present favorable responses to ioidine. Itraconazole is a fungistatic drug, fungicidal only in high doses. For this reason, if the fungistatic dose is not administered for sufficient time, recurrences may occur. In the last three years, the state of Espirito Santo has become a new epidemiological scenario for sporotrichosis, and it is placed in the route of transmission, closely to Rio de Janeiro. Cats are the most affected animals and are commonly responsible for transmission to other species, including humans. The increase in cases of canine sporotrichosis requires its inclusion in the differential diagnosis of nodular-ulcerative lesions, along with cutaneous neoplasias and immune-mediated diseases.
\end{abstract}

Keywords: dermatology, zoonosis, dimorphic fungi, public health, mast cell tumour, vinblastine, prednisolone.

Descritores: dermatologia, zoonose, fungos dimórficos, saúde pública, mastocitoma, vimblastina, prednisolona. 


\section{INTRODUCTION}

Sporotrichosis is a fungal zoonosis highly prevalent in subtropical and tropical regions around the world, caused by the dimorphic fungi complex Sporothrix schenckii [1,4]. Transmission occurs through biting, scratching or contact with exsudates from lesions of diseased cats [4,13]. In Brazil, this dermatozoonosis has been described in Minas Gerais, São Paulo, Paraná, Rio Grande do Sul and Rio de Janeiro [8,13,16,17,19], nevertheless, in the state of Espírito Santo, it has only been reported in humans [9]. In the literature, there is a paucity of papers that mention transmission and ocurrence in cats and even fewer in dogs $[4,13]$.

Heretofore six species has been described and related to clinical sporotrichosis: $S$. brasiliensis, S. globosa, S. luriei, S. mexicana, S. albicans and $S$. schenckii sensu stricto. Sporothrix species differs according to its geographic distribution. Classically, the infection occurs through the traumatic implantation of the aetiologic agent in the dermis, through plant fragments or soil organic matter contaminated by fungal propagules of Sporothrix sp. [12].

This article aims to make the first description of a case of canine sporotrichosis in the state of Espírito Santo, Brazil. In the present report attention is given to its clinical presentation, which can mimic bacterial, neoplastic or immunomediated diseases $[9,13,18]$, but also to the fact that the patient's immune system might be compromised due to a diagnosis of malignancy followed by surgery and adjuvant chemotherapy, shortly before sporotrichosis presentation.

\section{CASE}

A 10 year-old Bull Terrier male dog was submitted scrotum ablation (and orchiectomy) and bilateral inguinal lymph node removal, due to a mast cell tumour, diagnosed as grade I / low-grade, with clean margins on histopathology. At the same event a palpebral nodule was removed and diagnosed as a melanoma. The dog was submitted to 12 intravenous infusion of vinblastine (Velban $\left.{ }^{\circledR}\right)^{1}\left[2 \mathrm{mg} / \mathrm{m}^{2}\right.$ - six sessions every seven days and the next six every 14 days], along with prednisolone (Alcort $\AA)^{2}\left[40 \mathrm{mg} / \mathrm{m}^{2}\right.$ every $24 \mathrm{~h}$, during seven days, followed by $25 \mathrm{mg} / \mathrm{m}^{2}$, every $24 \mathrm{~h}$, during 30 days and $25 \mathrm{mg} / \mathrm{m}^{2}$ every $48 \mathrm{~h}$, for 60 days].

Two months after finishing chemotherapy the dog presented with small non-ulcerated nodules on the head, and an ulcerated nodule in the nasal planum
(Figure 1A-B). The dog was unsatisfactory treated with cephalexin (generic drug $)^{3}[25 \mathrm{mg} / \mathrm{kg}$ every 12 h], during 30 days, associated with topical application of gentamicin $0.5 \mathrm{~g}$, sulfanilamide $5.0 \mathrm{~g}$, sulfadiazine $5.0 \mathrm{~g}$, urea $5.0 \mathrm{~g}$, vitamin A 120.000 UI, q.s.p $100.0 \mathrm{~g}$ excipient (Vetaglós) ${ }^{4}$. At further anamnesis, the pet's responsible reported that the dog had the habit of hunting cats that entered the residence, which raised the hypothesis of sporotrichosis.

The following was then carried out with fine needle aspiration of the injuries in the head and nasal planum, for cytological evaluation and fungal culture. The cytology revealed individual or grouped polygonal and spindle cells, presenting fine cytoplasmic granulation, marked anisocytosis and pleomorphism with high nuclei:cytoplasm ratio, binucleation, coarse chromatin and single nucleoli. There was no mitotic figures, but there was moderate count of neutrophils, plasma cells and macrophages, compatible with pyogranulomatous process associated to stroma activation. However, after 30 days, the microculture technique detected hyaline septated hyphae with unicellular conidia stained with the lactophenol blue solution and compatible with Sporothrix schenckii (Figure 2). Punch biopsy was also performed and histopathology revealed multifocal orthokeratotic and parakeratotic hyperkeratosis, marked multifocal ulceration and discontinuation of the epidermis, moderate espongiosis and inflammatory infiltration composed by large numbers of neutrophils, macrophages, lymphocytes and plasma cells. A few, circular yeasts with negative imaging halo were rarely seen in the interstitium and interior of macrophages (Figure 3). Treatment was then initiated with itraconazol (generic drug $)^{5}$ [10 mg/kg every $\left.24 \mathrm{~h}\right]$ until clinical remission, obtained after 60 days, maintaining it for 30 more days. Patient showed completed recovery, with no further complatints through a follow-up of more than 220 days.

\section{DISCUSSION}

Sporotrichosis is considered a rare disease in dogs, with isolated cases in the literature [18]. However, an increasing number of cases have been reported in Rio de Janeiro, associated with an epidemic outbreak in cats, from 1998 to 2009 [2,6,20]. In the present report, contact with cats was deemed an important risk factor, detected in the anamnesis, which allowed the inclusion of sporotrichosis as a differential diagnosis for the presented lesions. 
In humans, most infections become apparent in 1-3 weeks, however, the incubation period may reach three months $[5,12]$. The dog of the present report showed the first signs of sporotrichosis two months after the end of a chemotherapy treatment for a mast cell tumour, which despite the complete surgical excision and classification as a low grade, occurred in a location associated with poor prognosis (scrotum), which suggested the need for complementation [11]. Therefore, although it can not be proven, it is suggested that the patient in this study was infected during an immunosuppressive phase, as a relapse of pulmonary sporotrichosis reported in a 44-year-old American African man after treatment of an esophageal squamous cell carcinoma with radiation therapy along with chemotherapy with carboplatin and paclitaxel [10]. The risk of infection during chemotherapy and soon after its completion is one of the critical and limiting points in cancer treatment, greatly affecting the ability of the host to develop an adequate fungicidal response

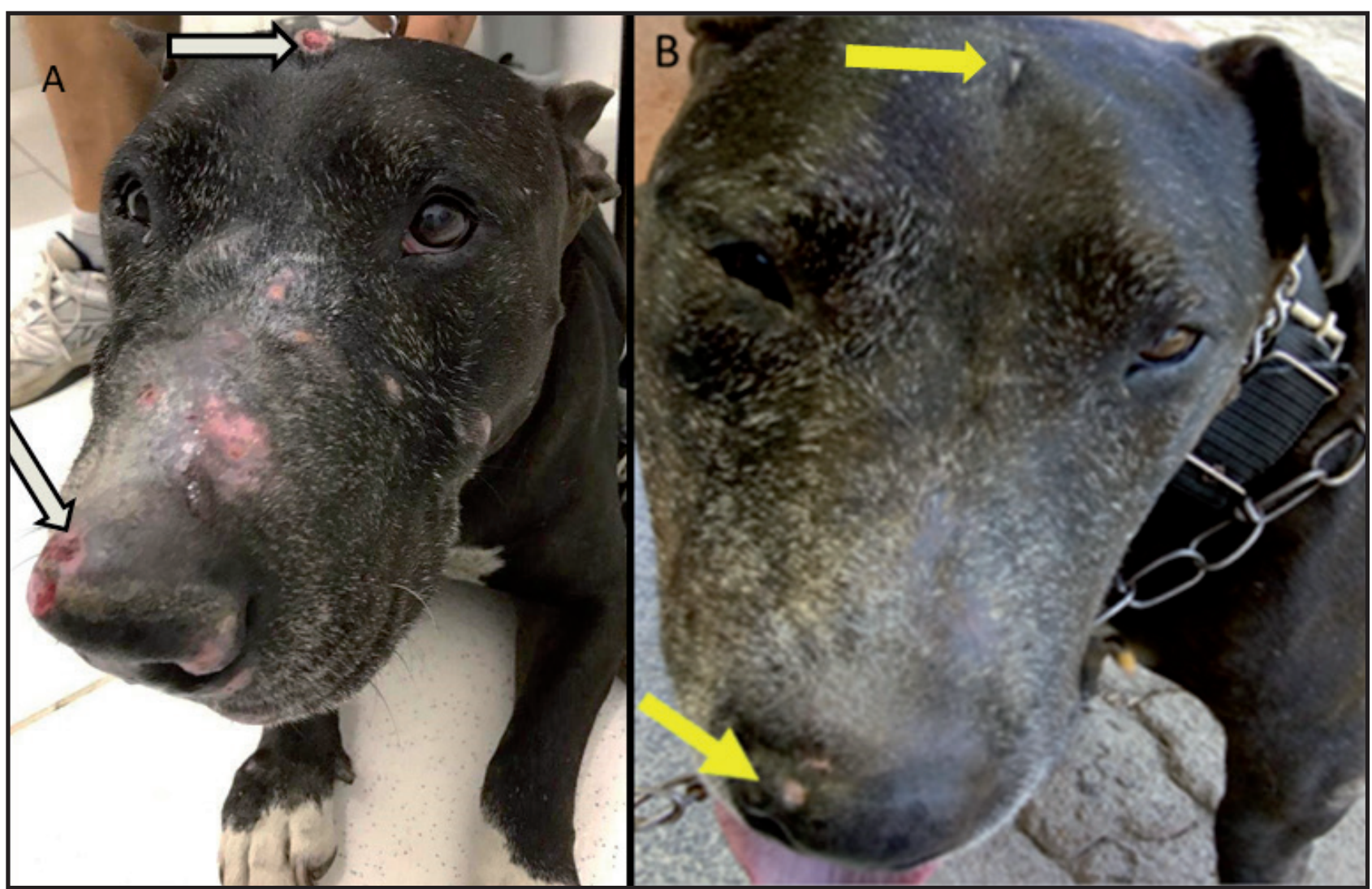

Figure 1. A- Patient 30 days after initiating treatment protocol with Itraconazole $10 \mathrm{mg} / \mathrm{kg} / \mathrm{SID}$ (white arrow). B- Remission of lesions beginning (yellow arrow).

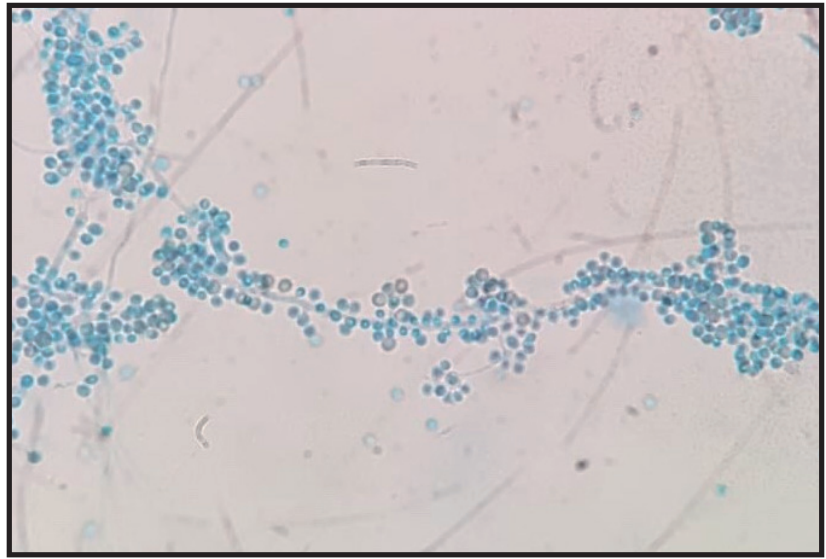

Figure 2. Photomicrograph of microculture technique showing hyaline septated hyphae with unicellular conidia stained with the lactophenol blue solution and compatible with Sporothrix schenckii [Lactophebol blue solution, $100 \mathrm{x}]$.

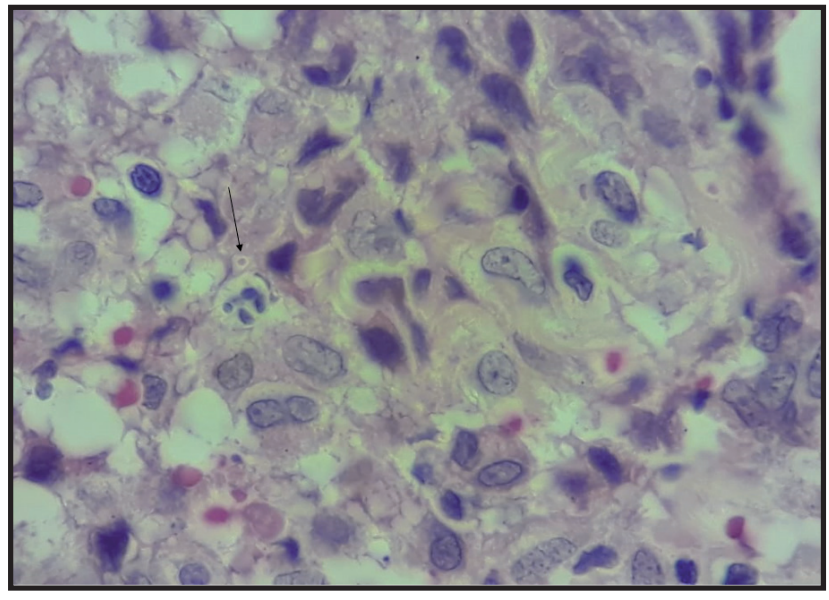

Figure 3. Nasal planum ulcerated lesion on histopathology. Mixed inflammatory infiltrate with circular yeasts with negative imaging halo (arrow) [HE, 100x]. 
due to the depletion of the immunity response [21-23]. Among other mechanisms, detrimental of innate response is related to reduction of the number and function of neutrophils, monocytes, Natural Killers, whilst impairment in adaptive immunity is mainly related to lymphocyte depletion. The same can occur with other immunosuppressive treatments, such as glucocorticoid, also included in the chemotherapeutic treatment of this patient, calcineurin inhibitors (cyclosporine) and mercaptopurine derivatives (azathioprine) $[3,14,15]$.

The patient presented small non-ulcerated nodules in the head region, and a nodule already ulcerated in the nasal plane, which had fast progression, according to the pet's responsible. The immune status of the host, infective load, lesion depth and temperature resistance are important factors that influence the clinical presentation of the disease in dogs $[4,5,13]$. The nodular / ulcerative form of the lesions presented by the patient made it possible to include, among the differential diagnoses, deep pyoderma, demodiciosis, dermatophytosis and sporotrichosis, but also immunomediated and neoplastic disease, including canine mast cell tumour itself, characterized by a wide lesion pleomorphism and heterogeneity in its biological behaviour [17].

The cytology of the lesion was one of the requested tests, however it was non diagnostic for the fungal lesion, showing only inflammatory infiltrate and stroma activation. In dogs, it is common for lesions to contain few yeasts, reducing the sensitivity of the method, as for histopathology, although this method allowed yeast's identification on this report $[4,5,13,16]$. However, after the collection and before the suspicion of sporotrichosis, it was essential to collect and send material for the fungal culture, considered the gold standard for its diagnosis [16]. On histopathological examination there was a few circular yeasts but elongated forms were not seen, as those forms are rarely present in dogs with sporotrichosis [20].

The therapy instituted was based on itraconazole at $10 \mathrm{mg} / \mathrm{kg}$, every $24 \mathrm{~h}$, obtaining a clinical cure within 60 days, but maintaining the treatment for another
60 days, as recommended. Yet, dogs usually presents favorable responses to iodide, at a dose of $20-40 \mathrm{mg} /$

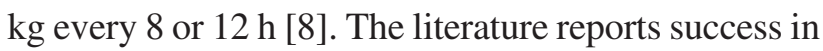
the treatment of feline sporotrichosis using itraconazole at the dose of $5-10 \mathrm{mg} / \mathrm{kg} /$ day [17]. However, it should be mentioned that itraconazole is a drug primarily fungistatic which may be fungicidal in high doses. For this reason, if the fungistatic dose is not administered for sufficient time, recurrences may occur [7].

In the last three years, Espírito Santo has become a new epidemiological scenario for sporotrichosis, but data have not yet been published $[4,5,13]$. Cats are the most affected animals and are commonly responsible for transmission to other species, including humans. However, this is the first non-human report in the state of Espírito Santo. The increase in cases of canine sporotrichosis requires its inclusion in the differential diagnosis of nodular-ulcerative lesions, along with cutaneous neoplasias and immune-mediated diseases. Fungal outburst should be included as a differential diagnosis for cutaneous and nasal lesions during and after cancer treatment. Moreover, considering the proximity of dogs and humans, and the zoonotic potential of sporotrichosis, attention should be paid to the diagnosis and correct treatment.

\section{MANUFACTURERS \\ ${ }^{1}$ Antibióticos do Brasil Ltda. Cosmópolis, SP, Brazil. ${ }^{2}$ CEPAV Pharma LTDA. São Paulo, SP, Brazil. \\ ${ }^{3}$ Teuto Brasileiro S/A. Anápolis, GO, Brazil. \\ ${ }^{4}$ Vetnil. Louveira, SP, Brazil. \\ ${ }^{5}$ Eurofarma Laboratórios S/A. São Paulo, SP, Brazil.}

Acknowledgements. To CAPES (Coordenação de Aperfeiçoamento de Pessoal de Nível Superior) for the author Carolina Magri Ferraz's scholarship grant - Finance Code 001; to CNPq (Conselho Nacional de Desenvolvimento Científico e Tecnológico) for the author Fabio Ribeiro Braga's productivity grant; to the FAPES (Fundação de Amparo à Pesquisa e Inovação do Espírito Santo).

Declaration of interest. The authors report no conflicts of interest. The authors alone are responsible for the content and writing of the paper.

\section{REFERENCES}

1 Alberici F., Paties C.T., Lombardi G., Ajello L., Kaufman L. \& Chandler F. 1989. Sporothrix schenckii var. luriei as the cause of sporotrichosis in Italy. European Journal of Epidemiology. 5(2): 173-177.

2 Almeida-Paes R., de Oliveira M.M., Freitas D.F., do Valle A.C., Zancope-Oliveira, R.M. \& Gutierrez-Galhardo M.C. 2014. Sporotrichosis in Rio de Janeiro, Brazil: Sporothrix brasiliensis is associated with atypical clinical presentations. PLoS Neglected Tropical Diseases. 8(9): 3094. 
3 Atencia S., Papakonstantinou S., Leggett B., McAllister H. \& Mooney C.T. 2014. Systemic fungal infection in a dog: a unique case in Ireland. Irish Veterinary Journal. 67: 1-5.

4 Bazzi T., Melo S.M.P., Fighera R.A. \& Kommers G.D. 2016. Características clínico-epidemiológicas, histomorfológicas e histoquímicas da esporotricose felina. Pesquisa Veterinária Brasileira. 36: 303-311.

5 Barros M.B.L., Schubach T.P, Coll J.O, Gremião I.D., Wanke B. \& Schubach A. 2010. Esporotricose: a evolução e os desafios de uma epidemia. Revista Panamericana de Salud Publica. 27: 455-460.

6 Barros M.B., Schubach A.O., Schubach T.M., Wanke B. \& Lambert-Passos S.R. 2008. An epidemic of sporotrichosis in Rio de Janeiro, Brazil: epidemiological aspects of a series of cases. Epidemiology and Infection.136: 1192-1196.

7 Catalán M. \& Montejo J.C. 2006. Antifúngicos sistémicos. Revista Iberoamericana de Micología. 23: 39-49.

8 Chomel B.B. 2015. Emerging and re-emerging zoonoses of dogs and cats. Animals. 4: 434-445.

9 De Araujo M.R., Anderson M., Fernandes G.F., De Camargo Z.P. \& De Hoog G.S. 2015. Human sporotrichosis beyond the epidemic front reveals classical transmission types in Espírito Santo, Brazil. Mycoses. 58: 485-490.

10 Farooqui S.M. \& Youness H. 2018. The infection returns: a case of pulmonary sporotrichosis relapse after chemotherapy. Case Reports in Medicine. 93: 1-4.

11 Horta R.S., Lavalle G.E., Costa M.P., Moura L.L., Marcinowska A. \& Araújo R.B. 2017. Outcome of adjuvant chemotherapy with lomustine, vinblastine and chlorambucil on management of canine mast cell tumour of high to intermediate risk. Arquivo Brasileiro de Medicina Veterinária e Zootecnia. 69: 1426-1436.

12 Kwon-Chung K. \& Bennet J. 1992. Sporotrichosis. In: Medical Mycology. Philadelphia: Lea \& Febiger: pp.707-729.

13 Larsson C. 2011. Esporotricose. Brazilian Journal of Veterinary Research and Animal Science. 48: 250-259.

14 Pavelski M., Seixas S.V., Warth J.F.G., Souza C., Dittich R.L \& Froes T.R. 2018. Fungal pneumonia in dogs and cats with pulmonary clinical signs in southern Brazil. Pesquisa Veterinária Brasileira. 38 (4): 696-702.

15 McAtee B.B., Cummings J.J., Cook A.K., Lidbury J.C., Haseltine J.C. \& Willard M.D. 2017. Oportunistic invasive cutaneous fungal infections associated with administration of cyclosporine to dogs with immune-mediated disease. Journal of Veterinary Internal Medicine. 31: 1724-1729.

16 Macêdo-Sales P.A., Souto S.R.L.S., Destefani C.A., Lucena R.P., Rocha E.M.S. \& Baptista A.R.S. 2018. Diagnóstico laboratorial da esporotricose felina em amostras coletadas no estado do Rio de Janeiro, Brasil: limitações da citopatologia por imprint. Revista Pan-Amazônica de Saude. 9: 13-19.

17 Madrid I.M., Mattei A.S., Fernandes C.G., Nobre M.O. \& Meireles M.C.A. 2012. Epidemiological findings and laboratory evaluation of sporotrichosis: a description of 103 cases in cats and dogs in Southern Brazil. Mycopathologia. 173: 265-73.

18 Montenegro H., Rodrigues A.M., Galvão Dias M.A., da Silva E.A., Bernardi F. \& Camargo Z.P. 2014. Feline sporotrichosis due to Sporothrix brasiliensis: an emerging animal infection in São Paulo, Brazil. BMC Veterinary Research. 10: 1-10.

19 Miranda L.H.M., Quintella L.P., Santos I.B., Menezes R.C., Figueiredo F.B., Gremião I.D.F., Okamoto T., Oliveira R.V.C., Pereira S.A., Tortelly R. \& Schubach T.M.P. 2009. Histopathology of canine sporotrichosis: a morphological study of 86 cases from Rio de Janeiro (2001-2007). Mycopathologia 168: 79-87.

20 Mascarenhas M.B., Lopes N.L., Pinto T.G., Costa T.S., Peixoto A.P., Ramadinha R.R. \& Fernandes J.I. 2018. Canine sporotrichosis: report of 15 advanced cases. Pesquisa Veterinária Brasileira. 38: 477-481.

21 Teoh F. \& Pavelka N. 2016. How chemotherapy increases the risk of systemic candidiasis in cancer patients: current paradigm and future directions. Pathogens. 5(1): 1-16.

22 Thomson M. 2007. Squamous cell carcinoma of the nasal planum in cats and dogs. Clinical Techniques in Small Animal Practice. 22(2): 42-45.

23 Vaan G.A.M., van Munter P.J.J. \& Bakkeren \& J.A.J.M. 1982. Recovery of immune function after cessation of maintenance therapy in acute lymphoblastic leukemia (ALL) of childhood. European Journal of Pediatrics. 139(2): 113-117. 